Research Paper:

\title{
Drug Cravings and Its Relationship With Family Com- munication Patterns and Resiliency Through the Media- tory Role of Difficulty in Cognitive Emotion Regulation
}

\author{
Ali Badie ${ }^{1}$ (D), Behnam Makvandi ${ }^{1^{*}}$ (D), Saeed Bakhtiarpour ${ }^{1}$ (D), Reza Pasha' ${ }^{1}$ (C)
}

1. Department of Psychology, Ahvaz Branch, Islamic Azad University, Ahvaz, Iran.

\begin{tabular}{|l|l|l|}
\hline $\begin{array}{c}\text { Use yourdevic to scan } \\
\text { and read thearticle online }\end{array}$ & $\begin{array}{l}\text { Cittation: Badie, A., Makvandi, B., Bakhtiarpour, S., Pasha, P., 2020. Drug Cravings and Its Relationship With Family Com- } \\
\text { munication Patterns and Resiliency Through the Mediatory Role of Difficulty in Cognitive Emotion Regulation. Journal of } \\
\text { Client-Centered Nursing Care, 6(2), pp. 125-134. https://doi.org/10.32598/JCCNC.6.2.329-1 }\end{array}$ \\
dol'https://doi.org/10.32598/JCCNC.6.2.329.1
\end{tabular}

\section{(1) (\$)}

Article info:

Received: 27 Jan 2020

Accepted: 03 Apr 2020

Published: 01 May 2020

Keywords:

Addiction, Cognitive, Emotion

Family, Communication,

Resilience

\begin{abstract}
A B S T R A C T
Background: Clients visiting Methadone Maintenance Treatment (MMT) clinics frequently face relapse during treatment. The present study was done to investigate the relationship between family communication patterns and resiliency and craving for drugs through the mediatory role of difficulty in cognitive emotion regulation among clients treated with methadone.
\end{abstract}

Methods: This descriptive correlational study was done on 213 drug addicts who referred to Ahvaz methadone treatment clinics in 2019, selected using convenience sampling. The research instruments included the Revised Family Communication Patterns (RFCP), the ConnorDavidson Resilience Scale (CD-RISC), the Cognitive Emotion Regulation Questionnaire (CERQ), and Craving Beliefs Questionnaire (CBQ). The proposed model was evaluated by path analysis using AMOS software.

Results: The results revealed a significant negative relationship between family communication patterns and the craving for drugs $(\mathrm{P}<0.01)$. There was a significant negative relationship between resiliency and craving for drugs in clients treated with methadone $(\mathrm{P}<0.01)$. Difficulties in cognitive emotion regulation had a mediating role in the relationship between family communication and resiliency with a craving for drugs $(\mathrm{P}<0.05)$.

Conclusion: According to the results of this study, the proposed model had a good fit. The family communication patterns as the external and environmental factors, and resiliency as an internal and psychological factor, affect control over negative emotions and craving for drugs. Therefore, they must be considered by therapists to keep the client in the process of treatment. 


\section{Highlights}

- Positive family communication patterns and resiliency had a negative effect on craving for drugs.

- There was a negative relationship between resiliency and family communication patterns with difficulty in cognitive emotion regulation.

- There was a positive and significant relationship between difficulty in cognitive emotion regulation and craving for drugs.

\section{Plain Language Summary}

Drug craving involves an extreme desire to abuse drugs, and if not satisfied, it will result in psychological and physical suffering, including weakness, loss of appetite, insomnia, aggressiveness, and depression. Various factors, such as resiliency, family communication patterns, and cognitive emotion regulation affect craving for drugs. According to the results, positive communication between family members and resiliency have a negative effect on craving for drugs, whereas difficulty in cognitive emotion regulation has a positive effect on craving for drugs.

\section{Introduction}

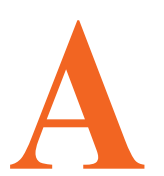

ddiction refers to a state of drug usage, in which quitting drugs is extremely difficult in terms of mental or physical pressures (Shabai, Mirzaian \& Sangani 2017). It is a multifaceted problem because several variables, including the craving for drugs (Koohestani et al. 2014), family communication patterns (Shafiabady et al. 2011), resiliency (Afshak \& Karami 2019), and cognitive emotion regulation (Esma'eali Shahna et al. 2017) can play a role in its development and continuation.

Craving for drugs plays a major role in explaining many dependency-related behaviors. In many modern definitions of drug dependency, craving is considered as a central phenomenon and the main factor for the continuation of drug abuse as well as addiction relapse after therapeutic interventions (Ekhtiari et al. 2006). Craving involves the extreme and sustained desire to abuse drugs, and if not satisfied, it will result in psychological and physical suffering, including weakness, loss of appetite, insomnia, aggressiveness, and depression (Addolorato et al. 2005). Moridi, Mowlaii Pardh \& Mohebbi (2017) reported that more than half of drug addicts have shown sudden relapse; they explained the reason for this recurrence as the lack of skills necessary for coping with high-risk situations and managing them.

Family is the main place for acquiring the skills necessary for controlling craving, as well as coping with risky situations. These skills are transferred to children through family communication patterns. Family is a unique communication system, which goes beyond and differs from friendly relations; its main value is the result of relations created by its members. Verbal and non-verbal information can be exchanged among family members by family communication patterns (Sacks et al. 2014). Through shaping the personality of individuals, family communication patterns can have important consequences for the personal and social lives of the members (Mahmud et al. 2011).

Failure of the parents to create favorable conditions for exchanging opinions as well as their failure to transfer and teach necessary attitudes, values, and coping skills will prevent children from mastering craving control methods (Bawalsah 2016). Goli, Emamipour \& Javanmard (2010) stated that life skills training leads to a negative attitude toward drugs. A study by Rahimi and Khayyer (2009) showed a positive relationship between conversation orientation and all the components of quality of life. Also, the quality, type, and frequency of conversations between parents and their teenage children, specifically focusing on smoking and its consequences will play a decisive role in reducing the likelihood of teenagers engaging in smoking.

Cognitive characteristics are very important for a desire to abuse drugs. Resiliency is one of these important cognitive characteristics, which is defined as the process, ability, or outcome of successful adaptation to threatening situations. Resiliency protects the individual against developing problematic behaviors and psychological damage, and despite the presence of adverse 
conditions, it guides the individual towards adaptive outcomes (Cheshme Sangi, Kord Tamini \& Kahrazei 2016).

Some of the basic characteristics of resilient people, which improve mental health are focus on problemsolving abilities, self-regulation, sense of purpose, and belief in a bright future. Reduced resiliency while facing life events is accompanied by a sense of mental pressure, anxiety, or depression (Zerbetto, Kord Tamini \& Kahrazei 2017). Resilient individuals have better mental health as well as a larger number of self-regulation skills along with higher self-esteem. Moreover, they are supported by their parents and are less likely to engage in risky behaviors, such as drug abuse (Momeni, Mowlaii Pardh \& Mohebbi 2013).

Difficulty in cognitive emotion regulation is another factor that seems to be influenced by family communication patterns and is associated with resiliency as well as drug abuse. Cognitive emotion regulation refers to the extent of the ability of the individual to identify and apply emotions to control thoughts, feelings, and behaviors despite being aroused for the intended action. Under such conditions, by trying to inhibit arousal, the individual may resist while facing craving and stimulation for engaging in unacceptable and destructive behaviors (Walters, Simons \& Simons 2018).

According to Alexander et al. (2019), emotion regulation refers to understanding the thoughts and judgments of the individuals about their abilities to reach the intended goal. The higher the level of emotion regulation, the lower the likelihood of craving for drugs and relapse. Accordingly, it seems that craving is controlled by automatic or non-automatic cognitive-emotional processes so that theories on craving generally emphasize the fact that the activation of emotions and motivations for searching drugs is related to the individuals' unaccept- able behaviors and desires (Kiani, Ghasemi \& Pourabbas 2013). Choubchian Langarudi and Zarbakhsh (2018) realized that emotion regulation, as one of the variables of coping strategies, had a significant relationship with the tendency to addiction. Davis et al. (2018) showed that difficulty in emotion regulation has resulted in a failure to adapt the conditions of quitting and the return to drug abuse among addicts, which leads to a real threat for the critical mental and physical balance of the individuals.

Therefore, based on the issues outlined above, the main objective of the current study was to investigate the relationship between family communication patterns and resiliency and craving for drugs through the mediatory role of difficulty in cognitive emotion regulation among clients treated with methadone. Figure 1 represents the proposed model of research design.

\section{Materials and Methods}

This descriptive correlational study was performed using path analysis. The statistical population of the study consisted of all drug addicts who referred to Ahvaz methadone treatment clinics in 2019 and 213 of whom were selected as the sample of the study using convenience sampling. The inclusion criteria were being treated in one of the methadone treatment clinics in Ahvaz city and declaration of written consent to participate in the study. The exclusion criterion included failure to completely answer all the questions. Ultimately, 213 questionnaires were analyzed. The participants gave their informed consent, in which information confidentiality was ensured.

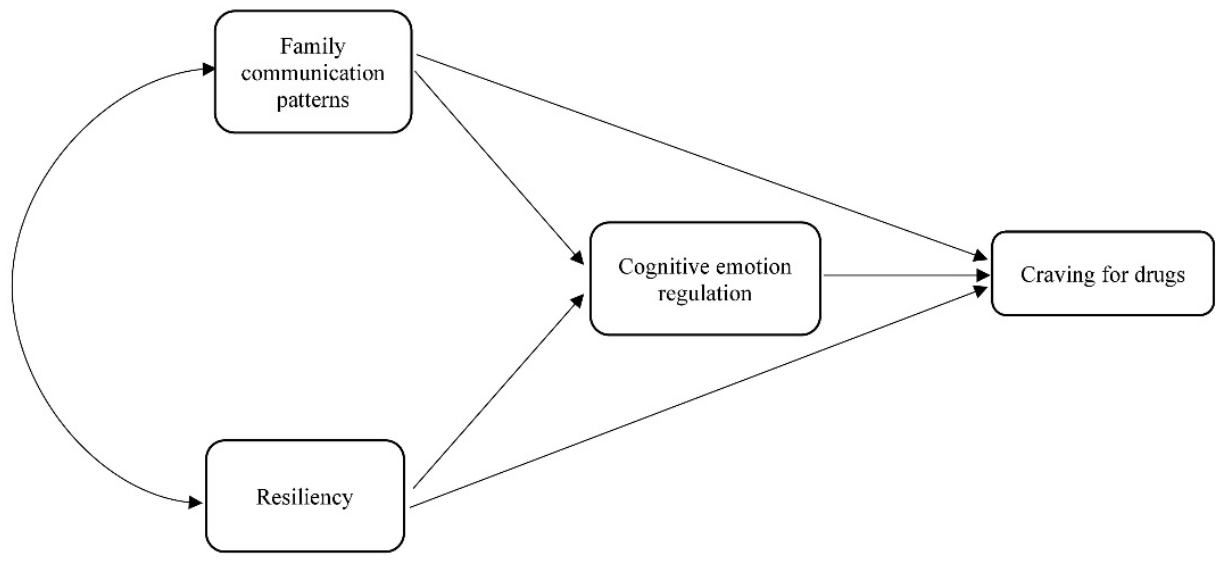

Figure 1. The proposed model of the research 


\section{Research instruments}

\section{The Craving Beliefs Questionnaire (CBQ)}

This questionnaire was developed by Beck et al. (1993). It is a self-report scale, which measures beliefs related to the craving for drugs. This questionnaire includes 20 items, which are scored on a 7- point Likert scale from 1 to 7. The overall score for this questionnaire ranges from 20 to 140 . Higher scores indicate higher craving, while low scores indicate low craving of the respondent. Rahmanian, Mirjafari \& Hasani (2006) reported Cronbach's alpha coefficient of 0.84 for the Persian version of the questionnaire. In the present study, the Cronbach's alpha coefficient was found to be 0.85 .

\section{Revised Family Communication Patterns (RFCP)}

This questionnaire, which was developed by Koerner and Fitzpatrick (2002), consists of 26 questions and is scored based on a 5-point Likert spectrum from 'completely disagree' (1) to 'completely agree' (5). The first 15 questions measure the subscale of conversation orientation, while the remaining 11 questions measure the subscale of conformity orientation. Higher scores in both of these subscales indicate that the high-conversationoriented families of families high in conformity orientation. Koerner and Fitzpatrick (2002) reported reliability of 0.89 for the conversation subscale and a reliability of 0.79 for the conformity subscale. Sepehri and Mazaheri (2009) reported Cronbach's alpha coefficient of 0.77 for the Persian version of the questionnaire. In this study, the reliability of the questionnaire was found to be 0.82 using Cronbach's alpha coefficient.

\section{The Connor-Davidson Resilience Scale (CD-RISC)}

Conner and Davidson (2003) designed this scale to measure resilience. This scale consists of 25 items scored based on a 5 -point Likert scale $(0=$ not true at all, $1=$ rarely true, $2=$ sometimes true, $3=$ often true, $4=$ true nearly all the time) to determine the individuals' resilience. The total score is obtained by the sum of the scores of all items. The total score ranges from 0 to 100 . The higher score indicates higher resilience. The cutoff point of this questionnaire is 50 . In other words, the scores of above 50 determine the resilient individuals. Conner and Davidson (2003) reported Cronbach's alpha coefficient of 0.88 for this questionnaire. Keyhani et al. (2015) reported Cronbach's alpha coefficient of 0.78 for the Persian version of this questionnaire. In the present study, Cronbach's alpha coefficient was found to be 0.85 .

\section{The Cognitive Emotion Regulation Questionnaire (CERQ)}

This questionnaire was designed by Garnefski \& Kraaij (2006). It is a multi-dimensional questionnaire measuring cognitive coping strategies while facing unfavorable incidents or situations. This questionnaire is a self-report tool with 36 items. It is scored based on a 5-point Likert scale ranging from 1 to 5 (never-always). CERQ includes the subscales of self-blame, acceptance, rumination, positive refocus, positive reappraisal, catastrophizing, and blaming others. Garnefski \& Kraaij (2006) reported the internal consistency of this questionnaire equal to 0.71 using Cronbach's alpha coefficient. The test-retest reliability of its subscales was reported to be $0.75-0.81$. Eesazadegan, Jenaabadi \& Saadatmand (2010) reported the reliability of the Persian version of this questionnaire to be 0.76 based on Cronbach's alpha coefficient. In this study, its Cronbach's alpha was 0.88 .

\section{Data analysis}

Data were analyzed by SPSS and AMOS software using descriptive and inferential statistics, such as mean, standard deviation, minimum and maximum scores, and Pearson correlation coefficient. The skewness and kurtosis were utilized to specify the data normality, and the path analysis was used to assess the proposed model

Table 1. Descriptive statistics of research variables $(n=213)$

\begin{tabular}{cccc}
\hline \multicolumn{1}{c}{ Vtatistical Indicators } & Mean \pm SD & Min. & Max. \\
\hline Family communication patterns & $57.53 \pm 18.75$ & 12 & 104 \\
Resiliency & $64.06 \pm 16.54$ & 18 & 99 \\
Difficulty in cognitive emotion regulation & $106.31 \pm 20.78$ & 46 & 164 \\
Craving for drugs & $66.32 \pm 22.12$ & 20 & 125 \\
\hline
\end{tabular}

Client- Centered Nursing Care 
Table 2. The one-sample Kolmogorov-Smirnov test results

\begin{tabular}{ccc}
\hline Variables & Kurtosis & Skewness \\
\hline Family communication patterns & 0.192 & 0.159 \\
Resiliency & 0.147 & -0.760 \\
\hline Difficulty in cognitive emotion regulation & -0.770 & 0.430 \\
\hline Craving for drugs & 0.040 & -1.100 \\
\hline
\end{tabular}

\section{Results}

The data of 213 participants were analyzed. Descriptive statistics, including Mean \pm SD of study variables, are presented in Table 1. Evaluating statistical assumptions, including values for skewness (all variables ranged -3 to +3 ) and kurtosis (all variables ranged -10 to +10 ), indicated the normal distribution of all the research variables (Table 2).

According to Table 3, there was a significant correlation between the correlation coefficients obtained for the research variables at the level of $\mathrm{P}<0.05$. In the proposed model, the four variables of craving for drugs, as the endogenous variable (criterion), family communication patterns and resiliency, as exogenous (independent) variables, and the variable of cognitive emotion regulation, as the mediatory variable, were evaluated. Table 4 presents the fitting indices for the proposed and final model.

Figure 2 shows the proposed and final model, in which the root mean square error of approximation (RM$\mathrm{SEA})=0.01, \chi^{2}=0.87, \chi^{2} \mathrm{df}=0.93$, and $\mathrm{CFI}=0.99$ indicated a good-fitting model.
According to Table 5, there was a direct, negative, and significant relationship between positive family communication patterns and difficulty in cognitive emotion regulation $(\beta=-0.309, P<0.01)$, and craving for drugs $(\beta=$ $-0.259, \mathrm{P}<0.01)$ among clients treated with methadone. There was also a direct, negative, and significant relationship between resiliency and difficulty in cognitive emotion regulation $(\beta=-0.285, \mathrm{P}<0.01)$, and craving for drugs $(\beta=-0.312, \mathrm{P}<0.01)$. There was a positive and significant relationship between difficulty in cognitive emotion regulation and craving for drugs $(\beta=0.238, \mathrm{P}<0.01)$.

The data presented in Table 6 indicate the indirect and significant effects of family communication patterns and resiliency on craving through the mediatory role of difficulty in cognitive emotion regulation.

\section{Discussion}

The present study was done to investigate the relationship between family communication patterns and resiliency and craving for drugs through the mediatory role of difficulty in cognitive emotion regulation among cases

Table 3. Pearson correlation coefficient between variables

\begin{tabular}{|c|c|c|c|c|}
\hline Variables & 1 & 2 & 3 & 4 \\
\hline Family communication patterns & 1 & & & \\
\hline Resiliency & 0.12 & 1 & & \\
\hline Difficulty in cognitive emotion regulation & $-0.35 *$ & $-0.32 *$ & 1 & \\
\hline Craving for drugs & $-0.30 *$ & $-0.20 *$ & $0.23 *$ & 1 \\
\hline
\end{tabular}

* $\mathrm{P}<0.05$

Client- Centered Nursing Care

Table 4. The proposed and final model fit indicators

\begin{tabular}{cccccccccc}
\hline Fit Indicators & $\boldsymbol{\chi}^{2}$ & df & $\boldsymbol{\chi}^{2} / \mathbf{d f}$ & GFI & AGFI & IFI & CFI & NFI & RMSEA \\
\hline Proposed and final model & 0.87 & 2 & 0.93 & 0.99 & 0.96 & 0.98 & 0.99 & 0.98 & 0.01 \\
\hline & & & & & & & & &
\end{tabular}




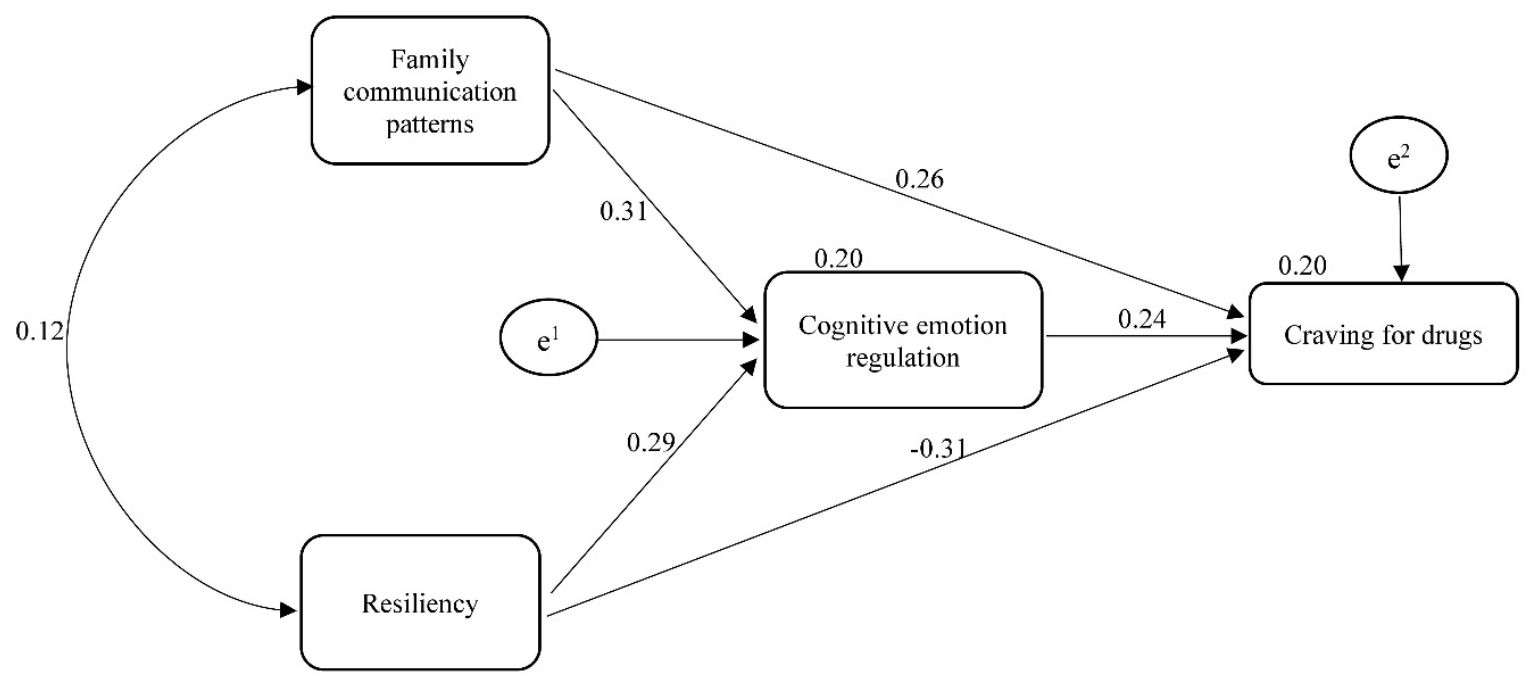

Client- Centered Nursing Care

Figure 2. The final model of the mediating role of difficulty in cognitive emotion regulation in the relationship between family communication patterns and resiliency and craving for drugs

treated with methadone. The findings of the present study on the presence of a significant direct relationship between family communication patterns and difficulty in emotion regulation and craving were in line with the results of other studies (Moridi et al. 2017; Rahimi \& Khayyer, 2009).

Moreover, comparing previous findings (Momeni et al. 2013; Kiani et al. 2013) with the findings of the current study indicates a level of agreement with regards to the direct and significant relationship between resiliency and difficulty in emotion regulation and craving. In other words, the absence of positive communication between family members and the lack of learning coping behaviors to deal with stressful situations and control negative emotions can increase the desire to re-use drugs. In addition, people with higher resiliency have more selfregulatory skills and are more resilient to the craving for drugs by controlling negative emotions.
The obtained results showed the indirect relationships between family communication patterns as well as resilience and craving through the mediatory role of difficulty in cognitive emotion regulation. This means that family communication patterns and resiliency through controlling difficulty in cognitive emotion regulation decreased craving for drugs in cases treated with methadone. In this study, the hypothesized relations were confirmed. From a theoretical point of view, the presence of positive communication patterns among family members and the creation of a favorable atmosphere for exchanging ideas and thoughts can result in the correct personality formation in family members (Mahmud et al. 2011) and learning coping behaviors, such as problem-solving, decision-making, and ability to refuse (Ghanbari Zarandi et al. 2018), as well as learning how to control and express emotions. Parents who fail to sufficiently transfer and teach attitudes, values, coping skills and the skills for controlling

Table 5. Path coefficients between research variables in the final standard model

\begin{tabular}{|cccccc}
\hline \multicolumn{1}{c}{ Path } & \multicolumn{4}{c}{ The Final Standard Model } \\
\cline { 2 - 6 } & Effect & $\boldsymbol{\beta}$ & B & SE & P \\
\hline Family communication patterns to difficulty in cognitive emotion regulation & Direct & -0.309 & -0.343 & -4.99 & 0.001 \\
\hline Resiliency to difficulty in cognitive emotion regulation & Direct & -0.285 & -0.358 & -4.60 & 0.001 \\
\hline Family communication patterns to the craving for drugs & Direct & -0.259 & -0.305 & -3.94 & 0.001 \\
\hline Resiliency to the craving for drugs & Direct & -0.312 & -0.418 & -4.80 & 0.001 \\
\hline Difficulty in cognitive emotion regulation to craving for drugs & Direct & 0.238 & 0.253 & 3.45 & 0.001 \\
\hline
\end{tabular}


Table 6. Results of the Bootstrap method for investigating indirect and intermediary paths

\begin{tabular}{|c|c|c|c|c|c|c|c|}
\hline \multicolumn{3}{|c|}{ Variables } & \multicolumn{5}{|c|}{ Final Standard Model } \\
\hline Predictor & Mediator & Criterion & Bootstrap & Lower limit & Upper limit & SE & $\mathbf{P}$ \\
\hline $\begin{array}{l}\text { Family communica- } \\
\text { tion patterns }\end{array}$ & $\begin{array}{l}\text { Difficulty in cognitive } \\
\text { emotion regulation }\end{array}$ & Craving for drugs & 0.087 & 0.048 & 0.144 & 0.030 & 0.007 \\
\hline Resiliency & $\begin{array}{l}\text { Difficulty in cognitive } \\
\text { emotion regulation }\end{array}$ & Craving for drugs & 0.091 & 0.038 & 0.127 & 0.036 & 0.016 \\
\hline
\end{tabular}

Client- Centered Nursing Care

negative emotions to their children will reduce their ability to overcome the craving for drugs (Goli et al. 2010).

In the absence of such skills, tense situations can increase the risk of addiction for the individual through impulsive responses and unchecked consumption of drugs. Tense situations increase the level of stress hormones, such as cortisol, while the cardiovascular system directs blood towards the muscles in order to prepare the body for the reaction. Chronic tensions increase the risk of developing tension headache, common cold, neck pain, and depression. Under such conditions, craving for drugs increases the temptation to relapse leading to abuse drugs (Davis et al. 2018), whereas resiliency, as an internal and cognitive factor, can increase cognitive emotion regulation by developing better coping mechanisms and defensive strategies. Reduced resiliency when encountering life events makes the individual feel a type of mental pressure, anxiety, or depression (Zerbetto et al. 2017).

Low level of emotion regulation leads to relapse among addicts because they are not capable of delaying pleasure. In other words, addicts prefer the immediate effects of drugs use, which relieves their physical suffering, to the benefits of quitting, which leads to physical and mental health (Davis et al. 2018). By increasing the levels of positive emotions, resiliency reinforces self-esteem, resulting in the positive adaptability and mental wellbeing of the individual. People with a higher level of mental wellbeing are more capable of adapting to problems. By improving the level of resiliency, the individual can resist and overcome issues that cause several psychological problems (Cortés, Méndez \& Aragón 2015).

With regard to the positive effect of resiliency on physical and mental health, some basic characteristics, such as being sociable, possessing problem-solving abilities, selfregulation, and having a sense of purpose and belief are emphasized. It has been reported that reduced resiliency against life events is accompanied by a sense of mental pressure, anxiety, or depression (Zerbetto et al. 2017). The ability obtained by resilience allows the person to manage difficult and stressful life situations and paves the way for their development and positive balance. All these abilities are effective in dealing with life situations and events and coping with problems with higher inner peace, leading to being safe against the craving for drugs (Görgülü, 2019).

\section{Conclusion}

According to the findings of the study, there was a significant relationship between family communication patterns and resiliency with craving for drugs through the mediatory role of cognitive emotion regulation. It is suggested that the therapeutic teams at addiction rehabilitation centers, including physicians, nurses, and psychologists, to consider the external and internal characteristics of the clients to control their craving for drugs. The current study had some limitations, such as being a cross-sectional study, the limitation of causal distinction in correlative studies, and the difficulty in generalizing the findings to other drug-dependent groups.

\section{Ethical Considerations}

\section{Complying with ethical guidelines}

The participants willingly filled out the questionnaires and signed written informed consent. The study was approved by the Ethics Committee of Islamic Azad University, Ahvaz branch (IR.IAU.AHVAZ.REC.1398.011).

\section{Funding}

The present paper was extracted from $\mathrm{PhD}$. thesis of the first author, Department of Psychology, Ahvaz Branch, Islamic Azad University.

\section{Conflict of interest}

The authors declared no conflict of interest. 


\section{Authors' contributions}

Conceptualization, Supervision: Ali Badie, Behnam Makvandi; Methodology: Ali Badie, Saeed Bakhtiarpour; Investigation, writing - review \& editing: All authors. Writing - original draft: Ali Badie, Behnam Makvandi, Reza Pasha; Funding acquisition, Resources: Ali Badie.

\section{Acknowledgments}

The authors would like to thank the staff and faculty members of the Department of Psychology, Islamic Azad University, Ahvaz Branch.

\section{References}

Addolorato, G., et al. 2005. Neurobiochemical and clinical aspects of craving in alcohol addiction: A review. $A d-$ dictive Behaviors, 3066), pp. 1209-24. [DOI:10.1016/j.addbeh.2004.12.011] [PMID]

Afshak, S., \& Karami, J., 2019. [The relationship between excitement and recursion with readiness for addiction in students (Persian)]. Rooyesh-e-Ravanshenasi Journal, 711), pp. 247-58. http://frooyesh.ir/article-1-484-en.html

Alexander, A., C., et al. 2019. Everyday discrimination indirectly influences smoking cessation through post-quit self-efficacy. Drug and Alcohol Dependence, 198, pp. 63-9. [DOI:10.1016/j.drugalcdep.2019.01.033] [PMID]

Bawalsah, J. A., 2016. Stress and coping strategies in parents of children with physical, mental, and hearing disabilities in Jordan. International Journal of Education, 8(1), pp. 1-22. [DOI:10.5296/ije.v8i1.8811]

Beck, A., et al. 1993. Cognitive therapy of substance abuse. New York: Guildford Press. https://books.google.com/ books?id=FQajDwAAQBAJ\&dq

Cheshme Sangi, Z., Kord Tamini, B. \& Kahrazei, F., 2016. [Role of assertive behavior in ego-resiliency and self-control in addicted women (Persian)]. Journal Research on Addiction, 10(38), pp. 163-82. http:/ / etiadpajohi.ir/article-1-826-en.htm

Choubchian Langarudi, H., \& Zarbakhsh, M. R., 2018. The relationship between psychological hardiness, coping styles, emotion regulation, and tendency toward addiction among students. Quarterly Journal of Family and Research, 15(3), pp. 31-50. http:/ /qjfr.ir/article-1-773-en.html

Connor, K. M., \& Davidson, J. R. T., 2003. Development of a new resilience scale: The Connor - Davidson Resilience Scale (CD-RISC). Depression and Anxiety, 18(2), pp. 76-82. [DOI:10.1002/da.10113] [PMID]

Cortés, J. M. G., Méndez. M. G. \& Aragón, S. R., 2015. Potencial resiliente en familias con adolescentes que consumen y no consumen alcohol. Acta Colombiana de Psicología, 18(2), pp. 163-72. [DOI:10.14718/ACP.2015.18.2.14]
Davis, J. P., et al. 2018. Substance use outcomes for mindfulness-based relapse prevention are partially mediated by reductions in stress: Results from a randomized trial. Journal of Substance Abuse Treatment, 91, pp. 37-48. [DOI:10.1016/j. jsat.2018.05.002] [PMID]

Ekhtiari, H., et al. 2006. [Evaluation of visual cues inducing drug craving in intravenous heroin users (Persian)]. Advances in Cognitive Sciences, 8(3), pp. 43-51. http://icssjournal.ir/article-1-209-en.html

Eesazadegan, A., Jenaabadi, H., \& Saadatmand, S., 2010. [The relationship between cognitive emotion regulation strategies, emotional creativity and academic performance with mental health in university students (Persian)]. Journal of Educational Psychology Studies, 712), pp. 71-92. [DOI:10.22111/JEPS.2010.717]

Esma'eali Shahna, M., Shalchi, B., \& Ahmadi, E., 2017. On the role of emotion regulation difficulties as a mediator in the relationship of family function and satisfaction of basic psychological needs with addictibility. Journal Research on Addiction, 11(42), pp. 248-29. http:/ /etiadpajohi.ir/article-1-1340-en.html

Garnefski, N., \& Kraaij, V., 2006. Cognitive emotion regulation questionnaire - development of a short 18-item version (CERQ-short). Personality and Individual Differences, 41(6), pp. 1045-53. [DOI:10.1016/j.paid.2006.04.010]

Ghanbari Zarandi, Z., et al. 2018. The assessment of difficulty in emotion regulation and craving based on the sensitivity of brain-behavioral systems and levels of loneliness. Quarterly Journal of Research on Addiction, 11(44), pp. 107-34. http://etiadpajohi.ir/article-1-1545-en.html

Goli, S., Emamipour, S., \& Javanmard, G., 2010. [The effects of teaching living skills on reduction of bias attention to the tempting stimuli related to drugs in people who have quit them (Persian). Journal Research on Addiction, 4(14), pp. 3142. http:/ / etiadpajohi.ir/article-1-384-en.html

Görgülü, T., 2019. The effect of self-efficacy and coping strategies on treatment motivation of individuals in the substance addiction group work process. Dusunen Adam, 32(1), pp. 33-42. [DOI:10.14744/DAJPNS.2019.00005]

Keyhani, M., et al. 2015. [Internal consistency and confirmatory factor analysis of the Connor-Davidson Resilience Scale (CD-RISC) among nursing female (Persian)]. Iranian Journal of Medical Education, 14(10), pp. 857-65. http://ijme. mui.ac.ir/article-1-3254-en.html

Kiani, A., Ghasemi, N., \& Pourabbas, A., 2013. [The comparsion of the efficacy of group psychotherapy based on acceptance and commitment therapy, and mindfulness on craving and cognitive emotion regulation in methamphetamine addicts (Persian)]. Journal Research on Addiction, 6(24), pp. 27-36. http:/ / etiadpajohi.ir/article-1-308-en.html

Koerner, A. F., \& Fitzpatrick, M. A., 2002. Understanding family communication patterns and family functioning: The roles of conversation orientation and conformity orientation. Communication Yearbook, 26, pp. 36-68. [DOI:10.1207/ s15567419cy2601_2]

Koohestani, Z., et al. 2014. [Survey of affecting factors the lapse among the Patients referring voluntarily to addiction-abandoning centers in Esfarayen (Persian)]. Journal of North Khorasan University of Medical Sciences, 5(5), pp. 1145-51. [DOI:10.29252/jnkums.5.5.S5.1145] 
Mahmud, Z., et al. 2011. Family communication, sibling position and adolescents' sense of responsibility. World Applied Sciences Journal, 14, pp. 74-80. https://www.researchgate. net/publication/289701579_Family_communication_sibling_ position_and_adolescents'_sense_of_responsibility

Momeni, K., Mowlaii Pardh, A., \& Mohebbi, Z., 2013. [The relation of resiliency and attachment styles to tendency to Students addiction (Persian)]. Quarterly Journal of Kermanshah Police Science, (12), pp. 11-20. http://kermansha.jrl. police.ir/article_16408.html

Moridi, M., et al. 2017. [The survey of relapse's styles among drug users and stimulants (Persian)]. Pajouhan Scientific Journal, 15(3), pp. 10-5. [DOI:10.21859/psj-15032]

Rahimi, M., \& Khayyer, M., 2009. [The relationship between family communication patterns and quality of life of high school students in Shiraz (Persian)]. Studies in Education \& Psychology, 10(1), pp. 5-25. https://www.sid.ir/fa/Journal/ ViewPaper. aspx?id=96963

Rhhmanian, M., Mirjafari, S. A., \& Hasani, J., 2006. [The relationship between craving and attentional bias in opioid dependent relapsed and abstinent individuals (Persian)]. Iranian Journal of Psychiatry and Clinical Psychology, 12(3), pp. 216- 22. http://ijpcp.iums.ac.ir/article-1-5-en.html

Sacks, V., et al. 2014. The family environment and adolescents well-being [Internet]. Cited 14 October 2020, https://nahic. ucsf.edu/wp-content/uploads/2015/01/2014-52FamilyEnvironmentRB.pdf

Sepehri, S., \& Mazaheri, M., 2010. [Patterns of family communication and personality variables among college students (Persian)]. Journal of Developmental Psychology, 6(22), pp. 141-50. http://jip.azad.ac.ir/article_512327.html

Shabai, H., Mirzaian, B., \& Sangani, A. R., 2017. Structural equation modeling of schemas and attachment styles with addiction potential through the mediation of stress coping strategies, cognitive emotion regulation, and loneliness among the addicts under treatment. Journal of Research on Addiction, 11(43), pp. 177-94. http://etiadpajohi.ir/article-1-1479-en.html

Shafiabady, A., et al. 2011. [Comparing interactions pattern in families with and without substance dependent member and providing appropriate interventionist strategies (Persian)]. Family Counseling and Psychotherapy, 1(3), 264-83. http://fcp.uok.ac.ir/article_9454_en.html

Walters, K. J., Simons, J. S., \& Simons, R. M., 2018. Self-control demands and alcohol-related problems: Within-and betweenperson associations. Psychology of Addictive Behaviors, 32(6), pp. 573-82. [DOI:10.1037/adb0000387] [PMID] [PMCID]

Zerbetto, S. R., Galera, S. A. F., \& Ruiz, B. O., 2017. Family resilience and chemical dependency: Perception of mental health professionals. Revista Brasileira de Enfermagem, 706), pp. 1184-90. [DOI:10.1590/0034-7167-2016-0476] [PMID] 
This Page Intentionally Left Blank 